\title{
CARACTERIZAÇÃO DE ESCÓRIA DE ALTO FORNO PARA FABRICAÇÃO DE TELHAS*
}

Maria Célis Pinheiro da Silva ${ }^{1}$ Clara Giovana Souza Silva ${ }^{2}$ Alisson Clay Rios da Silva ${ }^{3}$

Sérgio Neves Monteiro ${ }^{4}$ Verônica Scarpini Candido 5

\section{Resumo}

Este estudo tem por objetivo caracterizar a escória de alto forno proveniente de uma siderúrgica do estado do Pará visando a sua incorporação em argilas para produção de telhas. O resíduo passou pela etapa de beneficiamento e, depois, foi realizada a difração de raios- $X(D R X)$ e fluorescência de raios- $X(F R X)$. Além disso, realizou-se também a análise morfológica por microscopia eletrônica de varredura (MEV). Os resultados mostraram que hematita, magnetita, goethite e wustita são as fases predominantes a associadas aos óxidos de ferro. A análise química por FRX mostrou que o resíduo apresenta elevados teores de sílica (SiO2) e óxidos de ferro associados a baixos teores de alumina (Al2O3). Dessa forma, a caracterização da escória de alto forno mostrou que esse resíduo apresenta-se como um potencial constituinte mássico cerâmico podendo contribuir par ao aumento da refratariedade das peças queimadas.

Palavras-chave: Caracterização; Cerâmica Vermelha; Escória e Alto Forno; Telhas.

\section{CHARACTERIZATION OF BLAST FURNACE SLAG FOR PRODUCTION OF} TILES

\section{Abstract}

This study aims to characterize the blast furnace slag from a steel mill in the state of Pará, aiming at its incorporation into clays for tiles production. The residue passed through the processing step and X-ray diffraction (XRD) and X-ray fluorescence (XRD) were performed. In addition, morphological analysis was performed by scanning electron microscopy (SEM). The results showed that hematite, magnetite, goethite and wustite are the predominant phases. The chemical analysis by FRX showed that the residue presents high levels of silica (SiO2) and iron oxide associated with low levels of alumina (Al2O3). Thus, the characterization of the blast furnace slag showed that this residue presents itself as a potential ceramic mass constituent and can contribute to increase the refractoriness of the fired pieces.

Keywords: Blast Furnace Slag; Characterization; Red Ceramics; Tiles.

1 Mestranda. Programa de Pós-graduação em Engenharia de Processos, Universidade Federal do Pará (UFPA), Belém - PA, Brasil.

2 Graduanda em Engenharia de Materiais, Faculdade de Engenharia de Materiais, Universidade Federal do Pará (UFPA), Ananindeua-PA, Brasil.

3 Químico industrial, Doutor em Ciência dos Materiais, Professor Adjunto I, Faculdade de Engenharia de Materiais, Universidade Federal do Pará (UFPA), Ananindeua-PA, Brasil.

4 Engenheiro de Materiais, PhD em Engenharia e Ciência dos Materiais, Professor, Programa de Pós-graduação em Engenharia de Materiais/Departamento de Engenharia mecânica e Materiais, Instituto Militar de Engenharia (IME), Rio de Janeiro, Rio de Janeiro, Brasil.

5 Bióloga, Doutora em Ciência dos Materiais, Professora Adjunta I, Faculdade de Engenharia de Materiais, Universidade Federal do Pará (UFPA), Ananindeua-PA, Brasil.. 


\section{INTRODUÇÃO}

$\mathrm{Na}$ atualidade vários estudos [1-2-3] apontam que a indústria vem se desenvolvendo com grande velocidade, por meio da inovação dos processos e de novos produtos, porém, todas essas transformações vêm acompanhadas de um aumento significativo da produção de resíduos, que passaram a ser uma das maiores preocupações da sociedade moderna [2].

A Norma Regulamentadora - NR 25 resíduos industriais, define como como tal aqueles provenientes dos processos industriais, na forma sólida, líquida ou gasosa ou combinação dessas, e que por suas características físicas, químicas ou microbiológicas não se assemelham aos resíduos domésticos, como cinzas, lodos, óleos, materiais alcalinos ou ácidos, escórias, poeiras, borras, substâncias lixiviadas e aqueles gerados em equipamentos e instalações de controle de poluição, bem como demais efluentes líquidos e emissões gasosas contaminantes atmosféricos. [4]

Com relação aos resíduos sólidos, destaca-se a indústria cerâmica por ser uma das que mais se destacam na reciclagem de resíduos industriais e urbanos, em virtude de possuir elevado volume de produção que possibilita o consumo de grandes quantidades de rejeitos e que, aliado às características físico-químicas das matérias-primas cerâmicas e às particularidades do processamento cerâmico, faz da indústria cerâmica como uma das grandes opções para a reciclagem de resíduos sólidos. [1-5-6]

Há de se ressaltar a questão da sustentabilidade e o uso racional dos recursos naturas, assim como, há um movimento para que as organizações sejam mais sustentáveis em suas ações, serviços, produtos e em seus processos industriais. Este cenário remete à possibilidade de se verifique a possibilidade de melhorias da incorporação de resíduos industriais na cerâmica, visando à manutenção das propriedades dos produtos e redução do impacto ambiental [6-7-8].

A determinação das propriedades tecnológicas como resistência mecânica, retração de queima e absorção de água são essências para a garantia de um produto final de qualidade e que tenha boa aceitabilidade no mercado [9]. Nas indústrias de cerâmica vermelha, geralmente, não é feito um estudo preliminar dos constituintes mássicos para a fabricação das peças, o que pode acarretar em produtos fora das normas brasileiras.

Nessa perspectiva, já se pode encontrar estudos que visam discutir acerca dos resíduos sólidos produzidos na indústria da cerâmica vermelha, apontando alternativas para seu descarte e incorporação em outros processos produtivos, de forma a reduzir os custos com a disposição final e contribuir com o desenvolvimento econômico da Indústria. [10]

Nesse contexto, esse trabalho tem como objetivo caracterizar, química e mineralogicamente, a escória de alto forno proveniente da atividade siderúrgica do estado do Pará.

\section{MATERIAIS E MÉTODOS}

A escória de alto forno foi obtida de uma siderúrgica localizada no estado do Pará e, após sua obtenção, o resíduo foi encaminhado à Usina de Materiais da Universidade Federal do Pará.

A escória foi seca em estufa de modelo DIMATE, à temperatura de $110^{\circ} \mathrm{C}$ durante 24h. Após essa etapa o material foi conduzido para o moinho de bolas de modelo Work Index série 005, onde foi realizada a etapa de desagregação, por um período de 30 minutos. 
Em seguida, o resíduo foi passado em peneira com abertura de 325 mesh e encaminhado para a análise mineralógica, química e morfológica. A difração de raios-X (DRX), foi realizada em amostras na forma de pó em difratômetro da Bruker, modelo D2- Phaser, operando a $30 \mathrm{kV}$ e $10 \mathrm{~mA}$ e com um comprimento de onda $\lambda \mathrm{CuKa}=1,5406 \AA$. As amostras foram examinadas em um intervalo de $2 \theta$ entre $0 \mathrm{e}$ $60^{\circ}$, a uma taxa de varredura de $8 \% \mathrm{~min}$.

A Fluorescência de raios-X (FRX) foi realizada utilizando o equipamento Axios Minerals da PANalytical e a análise morfológica das partículas foi feita utilizando um microscópio eletrônico de varredura de bancada Hitachi Analytical TableTop SEM TM3030.

\section{RESULTADOS} alto forno.

A tabela 1 apresenta o resultado da fluorescência de raios-x da escória de

Tabela 1. Composição química da escória de alto forno

\begin{tabular}{|c|c|}
\hline \multicolumn{2}{|c|}{$\begin{array}{c}\text { Escória de Alto } \\
\text { forno }\end{array}$} \\
\hline Componente & $\begin{array}{l}\% \text { em } \\
\text { peso }\end{array}$ \\
\hline $\mathrm{SiO} 2$ & 20,7 \\
\hline $\mathrm{Al} 2 \mathrm{O} 3$ & 6,38 \\
\hline $\mathrm{Fe} 2 \mathrm{O} 3$ & 20,1 \\
\hline TiO2 & 0,52 \\
\hline $\mathrm{MnO}$ & 1,84 \\
\hline $\mathrm{MgO}$ & 4,83 \\
\hline $\mathrm{CaO}$ & 26,7 \\
\hline $\mathrm{K} 2 \mathrm{O}$ & 0,48 \\
\hline $\mathrm{SO} 3$ & 0,46 \\
\hline $\mathrm{ZnO}$ & 0,58 \\
\hline $\mathrm{Cr} 2 \mathrm{O} 3$ & 0,15 \\
\hline PF & 50,8 \\
\hline
\end{tabular}

Nota-se que a escória de alto forno apresenta elevados teores de óxido de ferro. Esse resultado pode contribuir para conferir à cerâmica queimada a coloração avermelhada. As argilas encontradas no estado do Pará, geralmente, possuem baixos teores de óxidos de ferro o que confere as peças finais uma cor mais clara. Destaca-se também o elevado teor de sílica associado ao baixo teor de alumina fator que pode contribuir para aumentar a refratariedade das peças cerâmicas.

A análise por difração de raios- $x(D R X)$ da lama de alto forno está apresentada na figura 1 . 


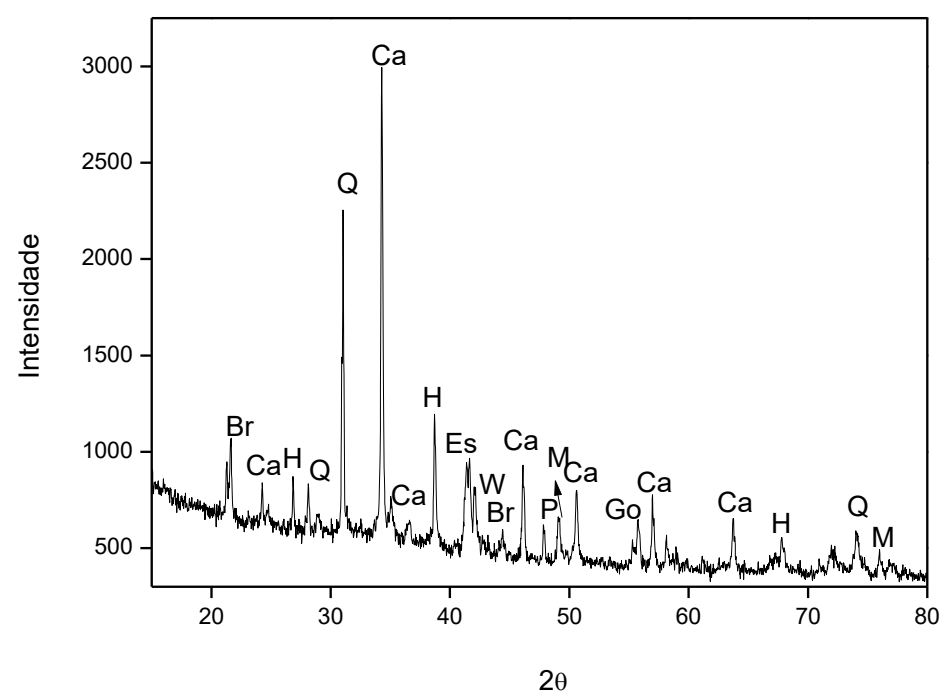

Figura 1. Difratograma de raios-x da escória de alto frono. Ca: calcita, Es: espinélios, Go: goetita, H: hematita M: magnetita, Q: quartzo, W: Wustita, Br: brucita, P: periclásio, Fr: franqulinita .

A análise por difratometria de raios-x da escória de alto forno revelou a presença de fases como a hematita, magnetita, franklinita, wustita que estão associadas a compostos de ferro. Além dessas fases associadas a óxidos ferro, fases como calcita, quartzo, brucita também foram observadas.

Devido à composição química complexa, ressalta-se que podem existir outras fases cristalinas minoritárias ou compostos amorfos eu não são identificados no difratograma.

A presença de calcita está associada ao óxido de cálcio que apresenta percentuais relativamente elevados na composição química da escória. Além disso, nota-se a presença de outras fases cristalinas como a brucita que está relacionada ao óxido de magnésio, assim como o periclásio. Destaca-se ainda que a elevada perda ao fogo observada pode estar relacionada à descarbonetação da calcita além da desidroxilação e/ou desidratação da goetita. figura 2.

A micrografia obtida por MEV da escória de alto forno está apresentada na

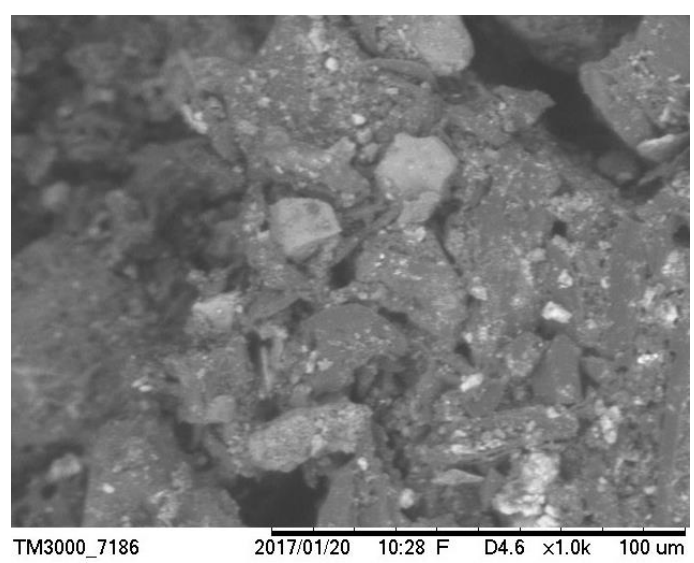

Figura 2. Micrografia obtida por MEV da escória de alto forno com aumento de 1000x. 
Nota-se que a escória de alto forno é composta por partículas mais claras que podem estar associadas ao quartzo e partículas de coloração mais escuras que podem estar associadas ao ferro. Observa-se também que as partículas não apresentam um padrão morfológico sendo possível observar partículas com diferentes formatos.

\section{CONCLUSÃO}

A caracterização da escória de alto forno revelou que o resíduo apresenta elevados teores de sílica associado a baixos teores de alumina, o que pode contribuir para o aumento da refratariedade das peças. Além disso, nota-se elevados teores de óxido de cálcio, cerca de $26,7 \%$ em peso. Esse teor é considerado alto e pode induzir a formação de patologias nas cerâmicas queimadas, por esse motivo, indica-se a incorporação de baixos teores de escória de alto forno. Destaca-se ainda que o resíduo é rico em óxidos de ferro o que pode contribuir para intensificar a cor avermelhada nas peças queimadas. Óxido de magnésio apresenta-se com concentração relativamente elevada no resíduo podendo contribuir para formação de fase líquida durante a queima. A análise por MEV mostrou a presença de partículas que podem estar associadas ao quartzo e aos óxidos de ferro.

\section{REFERÊNCIAS}

1 CMF Vieira, SN Monteiro. Incorporation of solid wastes in red ceramics - an updated review. Revista Matéria. 2009; 14(3): 881 - 905.

2 PHC Filogônio, AS Reis, DM Louzada,VP Della. Caracterização da lama da lapidação de vidros sodo-cálcicos para a formulação de produtos de cerâmica vermelha. 21ํㅡㄹ CBECIMAT - Congresso Brasileiro de Engenharia e Ciência dos Materiais, Cuiabá, 2014

3 CMF Vieira, CACM Dias, AV Mothé, R Sánchez, SN Monteiro. Incorporação de lama de alto forno em cerâmica vermelha. Revista Cerâmica, 2007; 53(328): 381-387.

4 HN Yoshimura, A Camargo, J Portela. Adição de Metais Tóxicos a Massas Cerâmicas e Avaliação de sua Estabilidade frente a Agente Lixiviante. Parte 2: Lixiviação. Cerâmica Industrial. 2005;10(4): 35-40.

5 RR Menezes, GDA Neves, HC Ferreira. O estado da arte sobre o uso de resíduos como matérias-primas cerâmicas alternativa. Revista Brasileira de Engenharia Agrícola e Ambiental. 2002; 6(2): 303-313.

6 MC Casagrande, MN Sartor, V Gomes, VP Della, D Hotza, AD Oliveira. Reaproveitamento de resíduos sólidos industriais: processamento e aplicações no setor cerâmico. Cerâmica Industrial. 2008; 13(1/2): 34-42.

7 AMB Becker Junior, AL Rodriguez, CM Mählmann, DAR Lopez. Estudo para análise de ciclo de vida de produtos cerâmicos. Revista Jovens Pesquisadores. 2013; 3(2): 122-133.

8 YM Paz, MM de Morais, RM de Holanda. Desenvolvimento Econômico Regional e o Aproveitamento de Resíduos Sólidos no Polo da Indústria da Cerâmica Vermelha de Pernambuco. Revista Brasileira de Geografia Física. 2014; 6(6):, 1682-1704.

9 MRC Oliveira, J Martins. Caracterização e classificação do resíduo sólido "pó do balão", gerado na indústria siderúrgica não integrada a carvão vegetal:- estudo de um caso na região de Sete Lagoas/MG. Química Nova. 2003; 26(1): 5-9.

10 PS Santos. Ciência e Tecnologia das Argilas. $2^{a}$ edição revisada e ampliada. São Paulo: Edgard Blücher Ltda. 1989. 